\title{
Diagnostic accuracy of the Tzanakis score for acute appendicitis in a resource-limited setting: A tertiary hospital-based survey
}

\author{
Ajak Makor', Josephat Jombwe², Moses Galukande', Alex E. Elobu' \\ 1. Department of Surgery, College of Health Sciences, Makerere University, Kampala, Uganda \\ 2. Department of Surgery, Mulago National Referral and Teaching Hospital, Kampala, Uganda \\ Correspondence: Dr Alex E. Elobu (elobuemmy@yahoo.co.uk)
}

\begin{abstract}
C 2018 A. Makor et al. This open access article is licensed under a Creative Commons Attribution 4.0 International License (http://creativecommons.org/licenses/by/4.0/), which permits unrestricted use, distribution, and reproduction in any medium, provided you give appropriate credit to the original author(s) and the source, provide a link to the Creative Commons license, and indicate if changes were made.
\end{abstract}

East Cent Afr J Surg. 2018 Dec;23(3):100-103 https://dx.doi.org/10.4314/ecajs.v23i3.3

\begin{abstract}
Background

The management of acute appendicitis remains challenging with high peri-operative morbidity and mortality due diagnostic delay or high negative appendicetomy rates due to aggressive surgical approaches. CT scan is accurate for pre-operative diagnosis but not available or affordable in all settings. There remains a need for an affordable yet accurate tool for diagnosing acute appendicitis in the resource limited setting.

\section{Methods}

To determine the diagnostic accuracy of Tzanakis score in the preoperative evaluation of patients with acute appendicitis, we conducted a descriptive cross-sectional study at Mulago Hospital in Kampala, Uganda. Eligible consenting patients diagnosed with acute appendicitis consecutively underwent Tzanakis scoring and appendicectomy. Appencieal samples were sent for histological examination. Sensitivity, specificity, positive predictive value, negative predictive values, and diagnostic accuracy of the Tzanakis scoring system were calculated, relative to histological examination.
\end{abstract}

\section{Results}

We enrolled 160 participants of mean age 30.4 years with male:female ratio of 2:1. The Tzanakis score had sensitivity of 100\% (95\% Cl 98-100), positive predictive value $97 \%$ (95\% Cl 95-99), specificity of $64 \%$ (95\% Cl 31-89), negative predictive value of 100\%, and overall diagnostic accuracy of $98 \%$ with $3 \%$ negative appendectomy rate.

\section{Conclusions}

The Tzanakis score is found to be a sensitive and specific tool that should be considered for preoperative diagnosis of acute appendicitis in resource limited settings.

Keywords: appendicitis, appendicectomy, acute abdomen, diagnosis, Tzanakis score, Uganda

\section{Introduction}

Since it was first described in $1886,{ }^{1}$ acute appendicitis has remained to be one of the most important clinical causes of acute abdominal pain and indication for emergency surgery. ${ }^{2}$ About $7-8 \%$ of the general population in the developed world will suffer from acute appendicitis in their lifetime. ${ }^{3}$ To this day, accurately diagnosing acute appendicitis remains a challenge. ${ }^{4-5}$ Delays in diagnosing acute appendicitis could result in perforation and peritonitis in up to $15-30 \%{ }^{6-7}$ of patients resulting in higher peri-operative morbidity and mortality. ${ }^{6}$ In order to minimize these complications of delayed diagnosis and treatment, aggressive surgical intervention (especially when diagnosis is equivocal) has been advocated for. ${ }^{8}$ However, this aggressive surgical intervention more frequently results in the removal of normal appendices with negative appendectomy rates of 15 to $37.6 \% .^{9-10}$ This may lead to avoidable peri-operative morbidity, mortality cost of health care and delay in identifying the correct diagnosis and its prompt treatment. ${ }^{11}$ It is therefore of utmost importance to accurately diagnose acute appendicitis and offer timely and appropriate treatment.

In attempts to improve the clinicians' ability to diagnose acute appendicitis, numerous scoring systems have been developed but each has its challenges that have limit- 
ed their universal applicability. ${ }^{6}$ Computerized Tomography (CT) Scanning has fast become the diagnostic modality of choice for pre- operative evaluation of patients suspected to have acute appendicitis. ${ }^{12-13}$ However, CT scans are not widely available or affordable, more so in resource limited settings. ${ }^{14}$ The purpose of this paper therefore was to determine the diagnostic accuracy of Tzanakis score in the diagnosis of acute appendicitis.

\section{Methods}

Following ethical approval from the School of Medicine Research and Ethics Committee, we carried out this descriptive cross sectional study at Mulago National Referral and Teaching Hospital, Uganda. The researchers assessed patients for eligibility at the surgical unit of the Accidents and Emergency department. We prospectively enrolled consecutive consenting participants with a clinical diagnosis of acute appendicitis who eventually underwent emergent appendectomy between July 2014 and April 2015.

We performed a clinical assessment including Tzanakis Scoring followed by emergency appendectomy which was performed under general anesthesia by the attending staff surgeons after standard resuscitation and initiation of intravenous antibiotic therapy (ciprofloxacin and metronidazole). A consultant staff pathologist performed the histological examination of the removed appendix using hematoxylene and eosin staining.

The Tzanakis score was developed by Nikolaos Tzanakis and colleagues in 2005 in a quest for a cost effective tool for pre-operative diagnosis of acute appendicitis. ${ }^{15}$ The variables of Tzanakis scoring system as described in previous validity studies were: Ultrasound positive for acute appendicitis (6 points), tenderness in the right lower abdominal quadrant (4 points), rebound tenderness ( 3 points) and a leukocyte count of $\geq$ $12,000 / \mathrm{L}$ ( 2 points). ${ }^{15} \mathrm{We}$ considered a cut off of $\geq 13$ as highly suggestive of acute appendicitis. ${ }^{15}$ We compared the Tzanakis score to histological examination which is the Gold Standard for confirming the diagnosis of acute appendicitis. We calculated Sensitivity, Specificity, Positive and negative predicative values and over- all diagnostic accuracy with their 95\% Confidence Intervals. There was no blinding.

Abdominal ultrasonography was performed by an ultrasonographer using Philips HD3 brand with a linear $6 \mathrm{MHz}$ probe. We considered ultrasonography positive if any four of the following were present; (i) aperistaltic non compressible blind ended sausage shaped structure arising from the base of the cecum, (ii) Distinct appendiceal wall layers, (iii) an appendiceal outer diameter greater than $6 \mathrm{~mm}$, (iv) a target appearance of the appendix, (v) peri-appendicular fluid collection, (vi) echogenic prominent pericecal fat. Venous blood samples for white cell count were drawn by venepuncture in the left cubital fossa.

\section{Results}

Out of 1573 patients admitted in the study period, 160 (10.3\%) had a clinical diagnosis of acute appendicitis. We enrolled these 160 patients with clinically diagnosed acute appendicitis who underwent emergency appendectomy. The mean age for the study population was 30.4 years (SD 12.5), age range 5-69 years with a male to female ratio of 2:1.

All the 160 participants were resuscitated and given antibiotics before undergoing appendicectomy followed by histological examination of the removed appendix.

\section{Figure 1: Patient flow chart}

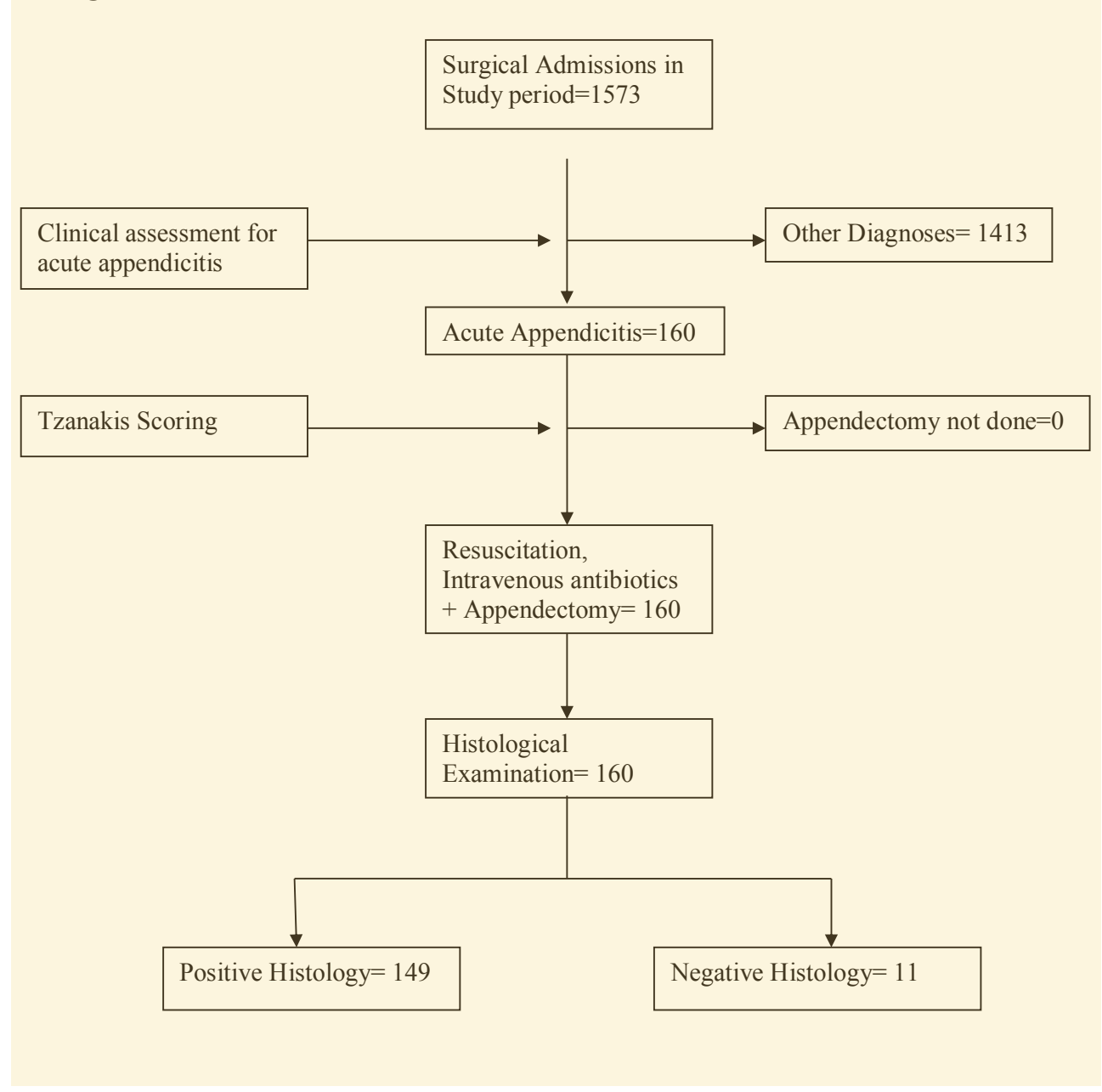


Table 1: Distribution of Tzanakis' score parameters:

\begin{tabular}{lll}
\hline Parameter & Frequency & Proportion (\%) \\
\hline Total White Blood Count & & \\
$\quad \geq 12000$ & 96 & $60 \%$ \\
$\quad \leq 12000$ & 64 & $40 \%$ \\
$\begin{array}{l}\text { Abdominal Ultrasound scan } \\
\quad \text { Positive }\end{array}$ & 155 & $96.88 \%$ \\
$\quad$ Negative & 5 & $3.12 \%$ \\
RLAQ Tenderness & 160 & $100 \%$ \\
$\quad$ Present & 0 & $0 \%$ \\
$\quad$ Absent & & \\
Rebound tenderness & 159 & 99. \\
$\quad$ Present & 1 & $0.63 \%$ \\
Absent & & \\
\hline
\end{tabular}

Table 2: Comparison of Tzanakis score to Histopathology.

\begin{tabular}{|c|c|c|c|c|c|}
\hline \multirow{3}{*}{$\begin{array}{l}\text { Tzanakis } \\
\text { Score }\end{array}$} & \multicolumn{4}{|c|}{ Histopathology } & \multirow[t]{3}{*}{ Totals } \\
\hline & \multicolumn{2}{|c|}{ Positive } & \multicolumn{2}{|c|}{ Negative } & \\
\hline & No. & $\%$ & No. & $\%$ & \\
\hline$\geq 13$ & 149 & 100 & 4 & 36 & 153 \\
\hline$\leq 13$ & 0 & 0 & 7 & 64 & 7 \\
\hline Total & 149 & & 11 & & 160 \\
\hline
\end{tabular}

Abdominal Ultrasound scan was positive for acute appendicitis in $97 \%$ of participants and the white cell count was raised in up to $60 \%$ of the participants

The Tzanakis scoring system had a sensitivity of $100 \%$ (95\% CI 98-100) with a Positive predictive value of $97 \%$ (95\% CI 95-99) and specificity of 64\% (95\% CI 31-89)with negative predictive of $100 \%$. The overall diagnostic accuracy was $98 \%$. Negative appendectomy rate was 3\% (4/153).

\section{Discussion}

We set to establish the accuracy of the Tzanakis score in the diagnosis of acute appendicitis. We registered an impressive performance of this scoring tool at sensitivity of $100 \%$ with positive predictive value of $97 \%$ compared to Histology. Our study population with average age of 30 years and male to female ratio of 2:1 was generally comparable in demographics and context to those of other studies on Tzanakis and other appendicitis scores. ${ }^{6,8,15}$

The performance of Tzanakis score in our study compares well to other studies where sensitivity of the Tzanakis score was $91 \%$ to $97 \% .^{15-17}$

The specificity of Tzanakis score was $64 \%$ with NPV of $100 \%$ which also compares well to the findings of other studies of Tzanakis score where specificity was $66 \% .{ }^{15-17}$ The specificity of Tzanakis score is thought to be generally low because of the inherent low specificity of Ultrasound scanning which is a significant contributor the total Tzanakis score for a patient. However, for a diagnostic test such as this, the more important value is its sensitivity and predictive value in the setting in which it is used so as to identify as many of the diseased persons as possible for whom appropriate and timely treatment can then be given. ${ }^{18}$ When the diagnosis is clear based on clinical features, clinicians have the right to exercise prudence and judgment to choose not to proceed with potentially unnecessary investigations and procedures.

With high sensitivity, PPV and overall diagnostic accuracy of $95 \%$, the Tzanakis score performed better than the more widely known and used Modified Alvorado Scoring System (MASS) whose sensitivity is $72 \%$ to $81 \% .^{17,19}$ An earlier study done at our very hospital revealed that MASS had sensitivity of $81 \%$ which is lower than that for Tzanakis score. Indeed the authors of that paper discouraged the use of MASS and recommended that ultrasonography be considered part of the preoperative evaluation for patients suspected to have acute appendicitis, especially if there is a diagnostic dilemma. ${ }^{19}$ This paper lends more strength to the need for our study and more so to the possible usefulness of its findings.

\section{Diagnostic value}

The preoperative diagnosis of appendicitis remains a challenge to many clinicians and mis-diagnosis of this condition is still common. ${ }^{4-5}$ Making an accurate pre-operative diagnosis of acute appendicitis is important to ensure that patients with the disease are offered appropriate and timely treatment while avoiding unnecessary treatment for those who do not have it.

With a PPV of $97 \%$, the Tzanakis score can pick up the vast majority of patients with acute appendicitis for whom appropriated intervention would then be given. In our study of Tzanakis score, only 4 out of 153 patients who had a positive test were revealed not to have acute appendicitis at histology giving a negative appendectomy rate of only $3 \%$. This compares well to other prior studies on Tzanakis score or pre-operative CT scanning with rates $\leq 6 \%^{12,16,17}$ and is comparatively lower than to negative appendectomy rates of 22$33 \%$ described for other scores especially MASS, ${ }^{5,9,20}$ and up to $37 \%$ for clinical diagnosis alone. ${ }^{9}$ Negative appendectomy comes with an otherwise avoidable perioperative morbidity and mortality and increased cost of care; moreover, it may leave the true diagnosis untreated. ${ }^{10}$ 
Also, with a NPV of $100 \%$, it means no patient with acute appendicitis was missed. This means that no patients would be left untreated only to later suffer the complications of delayed treatment for acute appendicitis.

With a diagnostic accuracy of $94 \%$, the Tzanakis score can be said to be comparable to CT scan whose diagnostic accuracy in acute appendicitis is up to $95 \% .{ }^{9,11}$ Although CT Scan which has established itself as the diagnostic test of choice for the pre-operative evaluation of patients suspected to have acute appendicitis, ${ }^{13}$ it is general unavailable or unaffordable in most resource limited settings. In Uganda, Ultrasound Scan services are comparatively more accessible and affordable than CT scan. This makes scoring systems such as Tzanakis score more appropriate for our resource limited setting.

\section{Limitations}

This study was conducted a tertiary hospital where the level of clinician expertise and types of patients may differ from lower levels of healthcare, and this limits the generalizability of our findings. Moreover, the extent of missing data should be considered when interpreting these findings; for example, if many patients presented late with clear signs of acute appendicitis, most scoring systems would tend to yield high positivity rates.

\section{Conclusions and recommendations}

Our study showed high performance of the Tzanakis score with sensitivity 100\%, PPV 97\% and over all diagnostic accuracy of $94 \%$ making it a worthwhile tool to consider for preoperative evaluation of patients with acute appendicitis. Further studies are required to evaluate the performance of the Tzanakis score against CT scan and also its performance at lower levels of health care.

\section{Competing interests}

All authors declare that they have no competing interests related to this work.

\section{References}

1. Fitz R. On Perforating Inflammation of the Vermiform Appendix with Special Reference to Its Early Diagnosis and Treatment. New England Journal of Medicine. 1935;213(6):245-8.

2. Stewart B, Khanduri P, McCord C, Ohene-Yeboah M, Uranues S, Vega Rivera F, et al. Global disease burden of conditions requiring emergency surgery. Br J Surg. 2014 Jan;101(1):e9-22.

3. Bhangu A, Søreide K, Di Saverio S, Assarsson JH, Drake FT. Acute appendicitis: modern understanding of pathogenesis, diagnosis, and management. The Lancet. [doi: 10.1016/S0140-6736(15)002755].386(10000):1278-87.

4. Ozturk A, Korkmaz M, Atalay T, Karakose Y, Akinci OF, Bozer M. The Role of Doctors and Patients in Appendicitis Perforation. Am Surg. 2017 Apr 01;83(4):390-3
5. Kryzauskas M, Danys D, Poskus T, Mikalauskas S, Poskus E, Jotautas $V$, et al. Is acute appendicitis still misdiagnosed? Open Med (Wars). 2016;11(1):231-6.

6. Wilasrusmee C, Anothaisintawee T, Poprom N, McEvoy M, Attia J, Thakkinstian A. Diagnostic scores for appendicitis: a systematic review of scores' performance. British Journal of Medicine and Medical Research. 2014;4(2):711-30.

7. Osime O, Ajayi P. Incidence of negative appendectomy: experience from a company hospital in Nigeria. The California Journal of Emergency Medicine. 2005;6(4):69.

8. Madiba TE, Haffejee AA, Mbete DL, Chaithram H, John J. Appendicitis among African patients at King Edward VIII Hospital, Durban, South Africa: a review. East Afr Med J. 1998 Feb;75(2):81-4.

9. Pena BM, Taylor GA, Lund DP, Mandl KD. Effect of computed tomography on patient management and costs in children with suspected appendicitis. Pediatrics. 1999 Sep;104(3 Pt 1):440-6.

10. Søreide K. The research conundrum of acute appendicitis. The British Journal of Surgery. 2015;102(10):1151-2

11. Rao PM, Rhea JT, Novelline RA, Mostafavi AA, McCabe CJ. Effect of computed tomography of the appendix on treatment of patients and use of hospital resources. N Engl J Med. 1998 Jan 15;338(3):1416.

12. Kim K, Kim YH, Kim SY, Kim S, Lee YJ, Kim KP, et al. Low-dose abdominal CT for evaluating suspected appendicitis. N Engl J Med. 2012 Apr 26;366(17):1596-605

13. Debnath J, George RA, Ravikumar R. Imaging in acute appendicitis: What, when, and why? Medical Journal Armed Forces India. [doi: 10.1016/j.mjafi.2016.02.005].73(1):74-9.

14. Adambounou K, Adjenou V, Salam AP, Farin F, N'Dakena KG, Gbeassor M, et al. A Low-Cost Tele-Imaging Platform for Developing Countries. Frontiers in Public Health. 2014;2:135.

15. Tzanakis NE, Efstathiou SP, Danulidis K, Rallis GE, Tsioulos DI, Chatzivasiliou $A$, et al. A new approach to accurate diagnosis of acute appendicitis. World J Surg. 2005 Sep;29(9):1151-6, discussion 7.

16. Malla BR, Batajoo H. Comparison of Tzanakis score vs Alvarado score in the effective diagnosis of acute appendicitis. Kathmandu Univ Med J (KUMJ). 2014 Jan-Mar;12(45):48-50.

17. Sigdel GS, Lakhey PJ, Mishra PR. Tzanakis score vs. Alvarado score in acute appendicitis. JNMA J Nepal Med Assoc. 2010 AprJun;49(178):96-9.

18. Maxim LD, Niebo R, Utell MJ. Screening tests: a review with examples. Inhalation Toxicology. 2014;26(13):811-28.

19. Nyeko JF. Evaluation of the modified Alvarado Score as a diagnostic tool for appendicitis. Unpublished work.

20. Kanumba ES, Mabula JB, Rambau P, Chalya PL. Modified Alvarado Scoring System as a diagnostic tool for acute appendicitis at Bugando Medical Centre, Mwanza, Tanzania. BMC Surg. 2011 Feb $17 ; 11: 4$ 